\title{
Decomposição de serrapilheira em bosque de sabiá na Zona da Mata de Pernambuco
}

\section{Joelma de Lira Freire ${ }^{1}$, José Carlos Batista Dubeux Júnior ${ }^{2}$, Mario de Andrade Lira ${ }^{3}$, Rinaldo Luiz Caraciolo Ferreira ${ }^{4}$, Mércia Virginia Ferreira dos Santos ${ }^{2}$, Erinaldo Viana de Freitas ${ }^{3}$}

\footnotetext{
1 Programa de Pós-graduação em Zootecnia-UFRPE.

2 Departamento de Zootecnia - UFRPE.

${ }^{3}$ Empresa Pernambucana de Pesquisa Agropecuária - IPA.

${ }^{4}$ Departamento de Ciência Florestal - UFRPE.
}

RESUMO - Objetivou-se avaliar a decomposição de frações de serrapilheira de sabiá (Mimosa caesalpiniifolia Benth) utilizando-se a técnica de sacos de náilon. Foram incubadas as seguintes frações de serrapilheira: folha senescente, folha no início da mineralização e ramos com até $20 \mathrm{~mm}$ de diâmetro. A incubação foi realizada nos períodos de 0, 4, 8, 16, 64, 100 e 256 dias nos anos de 2006 e 2007. As frações foram distribuídas em blocos ao acaso com cinco repetições. Foram avaliados os desaparecimentos de biomassa, nitrogênio $(\mathrm{N})$ e fósforo $(\mathrm{P})$, as concentrações de nitrogênio e fósforo e a relação carbono/ nitrogênio da serrapilheira ao longo dos períodos de incubação. De modo geral, o modelo exponencial negativo explicou o desaparecimento de biomassa, nitrogênio e fósforo, todavia, houve variação entre anos e, em alguns casos, apesar de significativos, os modelos apresentaram baixa correlação entre dados observados e preditos. A taxa de desaparecimento de biomassa foi lenta, uma vez que apenas $30 \%$ de biomassa de folhas foi mineralizada após 256 dias de incubação. A mineralização líquida de nitrogênio apresentou ampla variação entre anos e diferiu entre as frações estudadas. O teor de nitrogênio da serrapilheira incubada aumentou, em média, até os 32 dias (folhas) e até os 64 dias (ramos) de incubação, estabilizando-se em seguida. Foi usado o modelo platô linear para explicar esse processo. Com o passar dos períodos de incubação, a relação carbono/ nitrogênio diminuiu. Apesar de elevado teor de nitrogênio, a decomposição da serrapilheira de sabiá é lenta, o que pode reduzir as perdas de nutrientes no bosque, aumentando sua sustentabilidade e reduzindo os possíveis efeitos deletérios ao ambiente.

Palavras-chave: ciclagem de nutrientes, leguminosa arbórea, sistema silvipastoril

\section{Litter decomposition under a sabiá canopy in the Forest Zone in Pernambuco}

\begin{abstract}
The research aimed to evaluate the decomposition of sabiá (Mimosa caesalpiniifolia Benth) litter fractions by using the nylon bag technique. The following litter fractions were incubated: senescent leaves, leaves at the beginning of mineralization, and branches with diameter up to $20 \mathrm{~mm}$. Incubation was performed during periods of 0, 4, 8, 16, 64, 100, and 256 days in 2006 and 2007. The fractions were distributed in a random block design with five replications. It was evaluated the disappearance of biomass, nitrogen $(\mathrm{N})$, and phosphorus $(\mathrm{P})$, concentrations of nitrogen and phosphorus and the carbon/ nitrogen ratio of litter during the periods of incubation. In general, the negative exponential model explained the disappearance of biomass, nitrogen, and phosphorus, however, there was a variation among years and, in some cases, despite of being significant, the models showed a low correlation between predicted and observed data. Biomass disappearance rate was slow because only $30 \%$ of leaf biomass was mineralized after 256 days of incubation. Net nitrogen mineralization showed large variation among years, and it differed among the studied fractions. Nitrogen content of the litter increased, on average, until 32 days (leaves) and until 64 days (branches) of incubation followed by stabilization. The linear plateau model was used to explain that process. In the course of the incubation periods, the carbon/nitrogen ration decreased. Despite of the high content of nitrogen, the decomposition of sabiá litter is slow, what might reduce the loss of nutrients in the forest, increasing its sustainability and reducing the possible deleterious effects to the environment.
\end{abstract}

Key Words: arboreal legume, nutrient cycling, silvopastoral system

\section{Introdução}

O manejo adequado de resíduos vegetais possibilita otimizar a ciclagem de nutrientes e a sustentabilidade dos sistemas agrícolas. A quantificação de resíduos vegetais no fornecimento de nutrientes auxilia na definição de novas práticas de manejo, que otimizem a ciclagem de nutrientes e reduzam a demanda por insumos internos (Chagas et al., 2007).

A manutenção de ecossistemas agrícolas depende principalmente da deposição e decomposição de 
serrapilheiras. Dentre as espécies cultivadas que depositam serrapilheira, encontra-se a sabiá (Mimosa caesalpiniifolia Benth), leguminosa forrageira com acúleos, flores pequenas brancas, sementes pequenas e folhagem considerada uma valiosa fonte de alimento, contendo em média 17\% de proteína bruta (Souza \& Lima, 1982). Essa qualidade protéica encontrada é determinante para a decomposição desses resíduos (Sariyildiz et al., 2005; Wardle et al., 1995). Bonito et al. (2003) relataram que, quando a serrapilheira é rica em nitrogênio, ocorre rápida decomposição de resíduos.

A fertilidade do solo e a sustentabilidade dos sistemas agrícolas são dependentes da matéria orgânica do solo (Dubeux Jr. et al., 2004) que é mineralizada para a liberação de nutrientes (Souza \& David 2001).

Sariyildiz et al. (2005) relatam que a decomposição de serrapilheira depende da presença de organismos decompositores que apresentam baixos níveis de atividade quando o pH do solo é baixo (Begon et al., 1996). Segundo Gama-Rodrigues et al. (2003) e Bertol et al. (2004), a decomposição dos resíduos dos cultivos dependem da quantidade do material vegetal e do grau de fracionamento do resíduo e qualidade do microambiente.

Segundo Fernandes et al. (2006), a decomposição envolve grande variedade de micro-organismos do solo. Conforme Aita \& Giacomine (2003), as características da serrapilheira que influenciam a sua decomposição são os teores de nutrientes, lignina, polifenóis e a relação carbono/ nitrogênio. Altos teores de lignina conferem ao material difícil decomposição; a alta relação carbono/nitrogênio, por sua vez, leva à imobilização do nitrogênio, reduzindo assim a sua disponibilidade de $\mathrm{N}-\mathrm{NH}_{4}{ }^{+}$(amônio) e $\mathrm{N}-\mathrm{NO}_{3}{ }^{-}$ (nitrato) no solo.

O objetivo nesta pesquisa foi avaliar a decomposição e a contribuição de nutrientes das diferentes frações da serrapilheira de sabiá (Mimosa caesalpiniifolia Benth) nas condições da Zona da Mata de Pernambuco, visando estimar a reciclagem de nutrientes por esta via e, consequentemente, a necessidade de reposição de nutrientes para este ecossistema.

\section{Material e Métodos}

O experimento foi realizado na estação experimental de Itambé, pertencente ao Instituto Agronômico de Pernambuco - IPA, situada na Zona da Mata Setentrional, a $96 \mathrm{~km}$ de Recife. O clima é chuvoso, quente e úmido, com verão seco, temperatura média anual de $24^{\circ} \mathrm{C}$ e precipitação média anual de $1.200 \mathrm{~mm}$. A vegetação é classificada como Floresta Caducifólia e Subcaducifólia (CPRH, 2003).
O solo é classificado como argiloso vermelho-amarelo distrófico "A", de acordo com o sistema brasileiro de classificação de solos (Jacomine, 2001). Foi retirada uma amostra composta de solo no bosque para realização da análise de fertilidade (Tabela 1 ). As amostras foram retiradas em profundidades de 0-20 e 20-40 cm, e as análises, realizadas no laboratório de Fertilidade do Solo do Instituto Agronômico de Pernambuco - IPA, segundo metodologia da EMBRAPA (1997).

O experimento foi realizado em um bosque de sabiá com espaçamento de 4,5 m × 4,5 m e área de 0,11 ha. O bosque foi implantado em 1991 em uma área anteriormente ocupada com Brachiaria decumbens. Desde a implantação, o bosque foi manejado de diferentes formas, tendo recebido $200 \mathrm{~g}$ de superfosfato simples e esterco de curral curtido no ano de 1995 (Lima, 2008) e desramado por bovinos para avaliar a preferência de plantas com e sem acúleos. No período de agosto a outubro de 1998, foram coletados 38 fustes de forma proporcional ao tamanho do povoamento para determinação da biomassa. Foram considerados como fustes a porção das árvores compreendidas entre a altura de corte (nível do solo) e as primeiras ramificações na base da copa. (Moura et al., 2006).

Para avaliação da decomposição da serrapilheira foi utilizada a técnica de sacos de nylon (Dubeux Jr. et al., 2006). Os sacos utilizados tinham malha de $75 \mathrm{~mm}$ e mediam $30 \mathrm{~cm}$ $\times 30 \mathrm{~cm}$. Foram incubadas três frações de serrapilheira: folhas senescentes, folhas no início da mineralização e ramos com até $20 \mathrm{~mm}$ de diâmetro. As bolsas de náilon foram previamente secas em estufa a $60^{\circ} \mathrm{C}$ por 24 horas, sendo pesadas e colocadas as frações de serrapilheira correspondentes em cada saco (15 g/saco). Em seguida, os sacos foram colocados sob a superfície do solo e cobertos com serrapilheira, sendo incubados por 0, 4, 8, 16, 32, 64, $100 \mathrm{e}$ 256 dias. O ensaio foi realizado nos anos de 2006 e 2007 , sendo o primeiro período de avaliação de 5/4/2006 a 13/12/2006, e o segundo, de 6/3/2007 a 18/11/2007. Após o término de cada tempo de incubação, as bolsas eram limpas com pincel para a retirada dos resíduos impregnados e levadas para a estufa a $60^{\circ} \mathrm{C}$ por 72 horas.

Tabela 1 - Resultado da análise dos solos na profundidade de 0-20 e de 20-40 cm da área experimental

\begin{tabular}{lcccccc}
\hline Camada & Fósforo & $\mathrm{pH}\left(\mathrm{H}_{2} \mathrm{O}\right)$ & $\mathrm{K}^{+}$ & $\mathrm{Al}^{3+}$ & $\mathrm{Ca}^{2+}$ & $\mathrm{Mg}^{2+}$ \\
\cline { 4 - 7 } $0-20 \mathrm{~cm}$ & $\mathrm{mg} / \mathrm{dm}^{3}$ & & \multicolumn{4}{c}{$\mathrm{cmol}_{\mathrm{C}} / \mathrm{dm}^{3}$} \\
\cline { 4 - 7 } & 3 & 5,30 & 0,19 & 0,00 & 3,00 & 1,25 \\
$20-40 \mathrm{~cm}$ & 2 & 5,40 & 0,15 & 0,05 & 3,05 & 1,05
\end{tabular}

$\mathrm{P}$ = fósforo; $\mathrm{pH}=$ potencial hidrogênio-iônico; $\mathrm{K}$ = potássio; $\mathrm{Al}$ = alumínio; $\mathrm{Ca}=$ cálcio; $\mathrm{Mg}$ = magnésio. 
Foram determinados os teores de matéria seca (MS), matéria orgânica (MO), nitrogênio $(\mathrm{N})$ e fósforo $(\mathrm{P})$ de acordo com a metodologia descrita por Silva \& Queiroz (2002) e carbono (C), segundo metodologia descrita por Bezerra Neto \& Barreto (2004). As análises foram realizadas no Laboratório de Plantas e Ração da Empresa Pernambucana de Pesquisa Agropecuária (IPA).

As frações da serrapilheira e os tempos de incubação, em arranjo fatorial, foram distribuídos em delineamento em blocos ao acaso com cinco repetições. Os dados de decomposição da serrapilheira foram analisados por meio de curvas de desaparecimento ajustadas por modelo de regressão não linear exponencial pelo PROC NLIN do SAS (SAS Inst. 1996). Para avaliar o desaparecimento de biomassa, nitrogênio, fósforo e relação $\mathrm{C} / \mathrm{N}$, foi utilizado o modelo exponencial simples (Wagner \& Wolf, 1999) descrito pela equação: $X=$ Bo ${ }^{\text {e-kt }}$, em que: $X=$ proporção de biomassa (ou nutriente) remanescente no $\mathrm{T}$ dias, Bo = constante de desaparecimento.

O modelo descrito por McCartor \& Rouquette (1977) foi utilizado para ajustar a concentração de nutrientes com o passar do tempo. Foram calculados coeficientes de correlação de Pearson para os modelos aplicados. Após o ajuste do modelo apropriado para cada unidade experimental, os parâmetros de cada modelo utilizado (B0 e k para o exponencial negativo simples; b e T para o plateau linear) e para cada fração incubada foram analisados, usando-se o PROC Mixed do SAS (SAS, 1996). No caso de haver diferenças significativas entre os tratamentos, foram desenvolvidas equações para cada tratamento.

\section{Resultados e Discussão}

A decomposição da serrapilheira diferiu $(\mathrm{P}<0,0001)$ conforme o tempo de incubação, e as decomposições das frações folhas e ramos foram explicadas pelo modelo exponencial negativo. As folhas recém-caídas e folhas já em decomposição apresentaram decomposição semelhante e por isso foram agrupadas no mesmo conjunto de dados (folhas). As folhas apresentaram taxa de decomposição superior aos ramos, provavelmente pelo fato de os ramos apresentarem mais lignina (composto menos solúvel) dificultando sua decomposição (Figura 2). Era de se esperar, no entanto, decomposição mais rápida da serrapilheira, principalmente da fração folha. Em média, após 256 dias de incubação, apenas $30 \%$ da biomassa de folhas foi mineralizada. Em trabalho feito por Chagas et al. (2007), na decomposição e liberação de nitrogênio do feijoeiro, a palhada de vagens e as folhas senescentes apresentaram velocidades de decomposição similares, e os caules foram decompostos mais lentamente. Segundo os mesmos autores, a decomposição dos ramos foi mais lenta, possivelmente devido ao alto valor da relação carbono/nitrogênio que os caules apresentaram (>60) e provavelmente também pelo maior teor de lignina destes, dificultando assim a sua decomposição.

Houve diferenças $(\mathrm{P}<0,0001)$ entre frações da serrapilheira e interação entre as frações e os anos de incubação na mineralização líquida de nitrogênio (Figura 3). Para as folhas recém-caídas e senescentes, houve maior decomposição no ano de 2007 em relação ao ano de 2006. Fatores bióticos e abióticos interferem na decomposição de resíduos orgânicos, sendo estes fatores variáveis de ano para ano. Este fato demonstra a importância de estudos por períodos mais prolongados. Heal et al. (1997) relataram que a decomposição depende, dentre outros fatores, da qualidade da serrapilheira, temperatura do solo e umidade. É possível que a mineralização maior de nitrogênio em 2007 tenha ocorrido por causa da maior quantidade de chuvas nesse período (Figura 1), aumentando assim a umidade e favorecendo assim a decomposição pelos microorganismos do solo. Observa-se ainda imobilização de nitrogênio nos períodos iniciais de incubação das três frações de serrapilheira. Este fato provavelmente ocorreu devido à maior relação carbono/nitrogênio do material incubado nos períodos iniciais, levando à imobilização do nitrogênio do solo.

Apesar de os modelos apresentados terem sido significativos para mineralização de nitrogênio dos ramos, observa-se fraca correlação entre os dados preditos e observados para esta variável ( $r=0,01$ em 2006 e $r=0,13$ em

口Índice Pluviométrico Mensal aMédia Histórica 20 anos

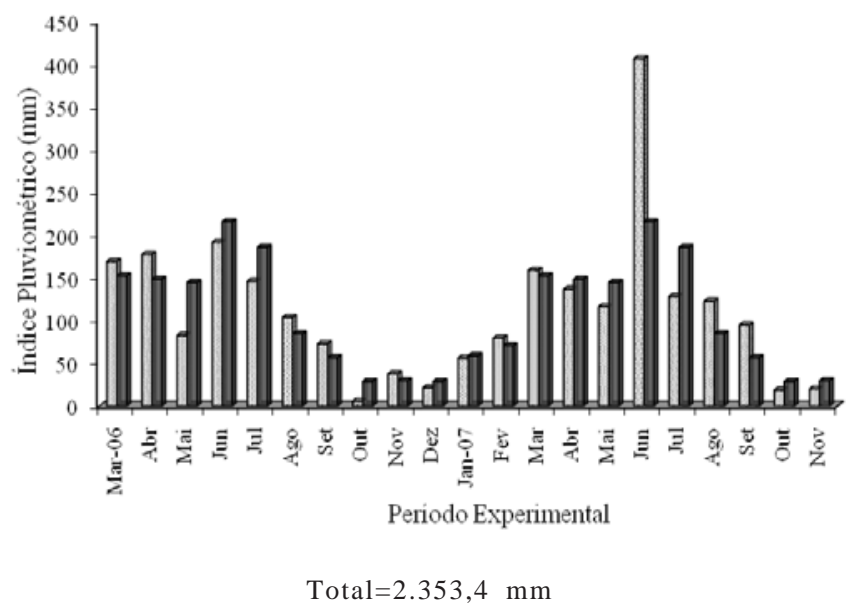

Figura 1 - Precipitação pluvial (mm) durante o período experimental e média histórica mensal. 


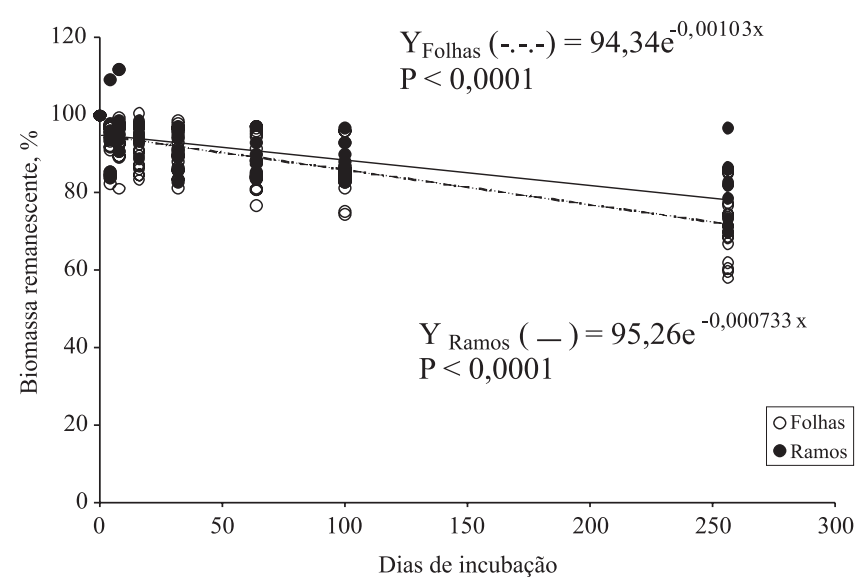

Contraste ortogonal de $\mathrm{k}$ para folhas vs. ramos $\mathrm{P}=0,04$; folhas senescentes vs. folhas recém-caídas $\mathrm{P}=0,11$.

Figura 2 - Biomassa remanescente (base na MS) das frações folhas e ramos de serrapilheira de sabiá em diversos períodos de incubação.

2007). Na mineralização líquida de nitrogênio de ramos, tanto em 2006 como em 2007, o nitrogênio remanescente ficou acima de $80 \%$ após 256 dias de incubação (ou seja, apenas $20 \%$ mineralizado), indicando menor qualidade dessa fração. Segundo Gonçalves et al. (2001), vários influenciam na mineralização do nitrogênio, entre eles, textura do solo, temperatura, umidade, $\mathrm{pH}$, grau de fertilidade do solo, interação solo-planta e o déficit de nitrogênio. Estes estão estreitamente relacionados com o esgotamento de carbono facilmente mineralizável, já que a dinâmica do nitrogênio está relacionada com a do carbono. De acordo com a análise do solo realizada na área experimental (Tabela 1), a baixa mineralização de nitrogênio pode ter sido em função do baixo $\mathrm{pH}$, diminuindo assim a ação de micro-organismos do solo sob o substrato.

Na mineralização líquida do fósforo (Figura 3), houve diferenças $(\mathrm{P}<0,0001)$ em relação aos anos e dias de incubação, tendo as três frações um padrão de decomposição semelhante. De forma semelhante aos de nitrogênio, os dados de 2006 foram mais dispersos que os de 2007. É possível que a maior mineralização de fósforo no ano de 2007 tenha ocorrido em função da maior quantidade de chuvas durante esse período, favorecendo assim a ação de micro-organismos do solo e, consequentemente, a decomposição. Aproximadamente $40 \%$ do fósforo foi mineralizado após 256 dias de incubação. Gama-Rodrigues et al. (2003) observaram menor liberação de fósforo em uma capoeira na Bahia do que na floresta natural, onde não apenas a qualidade do substrato regula o processo de mineralização e decomposição dos nutrientes da serrapilheira, mas também a qualidade do microambiente.
Como os teores de nitrogênio de folhas recém-caídas e folhas senescentes foram semelhantes, estes foram agrupados (Figura 4). Para folhas, o teor de nitrogênio aumenta até aproximadamente 32 dias de incubação; após esse tempo, o teor se estabiliza até os 256 dias. Nesse período de 32 dias, ocorreu aumento no teor de nitrogênio, que apresentou valores médios iniciais de 2,21\% elevando-se para 2,53\% após a estabilização. Provavelmente, o teor aumentou nesse período devido à imobilização de nitrogênio feita por micro-organismos do solo para decompor o material incubado. Além disso, compostos orgânicos menos recalcitrantes como açúcares solúveis e aminoácidos livres são rapidamente mineralizados no início da incubação, enquanto uma fração do nitrogênio está ligada à fibra, sendo de difícil decomposição. Dessa forma, ocorre um efeito de concentração do nitrogênio na biomassa incubada ao longo do período de incubação (Dubeux Jr. et al., 2006). Para a fração ramos, o teor de nitrogênio aumentou até os 64 dias de incubação; após esse período, o teor também se estabilizou até os 256 dias. Até os 64 dias de incubação, a fração ramos aumentou de 1,32\% para 1,62\% de nitrogênio. A explicação dada para a fração folha também se aplica aos ramos. Vale salientar o menor teor de nitrogênio dos ramos; entretanto, as folhas representam a maior parte da serrapilheira encontrada no bosque de sabiá.

Wood (1974) observou que houve aumento no teor de nitrogênio durante a decomposição do folhedo de Eucalyptus delegatensis, fato decorrido pela translocação do elemento principalmente pelas hifas de fungos. Segundo Coleman \& Crossley (1996), durante a decomposição, o nitrogênio é imobilizado pelos micro-organismos, resultando em aumento nos teores desse elemento na serrapilheira. Com a continuação do processo de decomposição, a relação carbono/nitrogênio diminui, tornando-se satisfatória para a ação microbiana. Vale salientar, no entanto, que, para períodos maiores de incubação, a relação lignina/N é mais correlacionada com o processo de decomposição, pois a lignina passa a ser um dos compostos recalcitrantes predominantes no material decomposto. Vuono et al. (1989) reportaram que o aumento do nitrogênio também pode ser atribuído à adição desse elemento por precipitações atmosféricas, restos de insetos, materiais caídos das árvores e imobilização para utilização pelos micro-organismos na elaboração de protoplasma.

A relação carbono/nitrogênio diminuiu na medida em que os dias de incubação aumentaram, tanto para folhas como para ramos, que apresentaram diferenças $(\mathrm{P}<0,0001)$ entre os tempos de incubação e as frações da planta (Figura 5). Segundo Taylor et al. (1989), a relação carbono/ nitrogênio é considerada o melhor parâmetro para estimar 
as taxas de decomposição, embora, para materiais submetidos a longos períodos de decomposição, ligninas e polifenóis podem ser mais adequados. A qualidade ou natureza dos compostos do $C$ e do nitrogênio é que faz essa diferença. Dubeux Jr. et al. (2006) relataram que a relação carbono/nitrogênio decresce com o passar dos tempos de incubação em função das frações mais solúveis de carbono se decomporem mais rapidamente, diminuindo assim essa relação.

Souto (2006) verificou que a relação carbono/nitrogênio da serrapilheira acondicionada nos sacos de nylon diminui em mais de $25 \%$ após 12 meses de exposição às condições ambientais, quando comparada com a inicial. Essa redução na relação carbono/nitrogênio possivelmente contribuiu para que houvesse equilíbrio entre a mineralização e a imobilização dos nutrientes na serrapilheira e, logo em seguida, maior liberação de N. Siqueira \& Franco (1988) comentam que quando a serrapilheira apresenta relação carbono/nitrogênio superior a 30:1, o nitrogênio fica imobilizado, e como consequência há redução na disponibilidade de $\mathrm{N}^{-\mathrm{NH}_{4}}{ }^{+}$(amônio) e N-NO3- (nitrato) no solo. Quando a relação fica entre 20-30:1, os processos de imobilização e mineralização se igualam, e abaixo de 20:1, ocorre a mineralização com a maior disponibilidade de compostos nitrogenados. A adição de quantidade elevada de resíduos culturais, com alta relação carbono/nitrogênio, faz com que os microrganismos quimiorganotróficos que atuam na decomposição da matéria orgânica se multipliquem gradativamente, diminuindo drasticamente as quantidades de nitrato e de amônio presentes no solo, predominando condições de pouca ou nenhuma disponibilidade de nitrogênio mineral para os vegetais superiores.
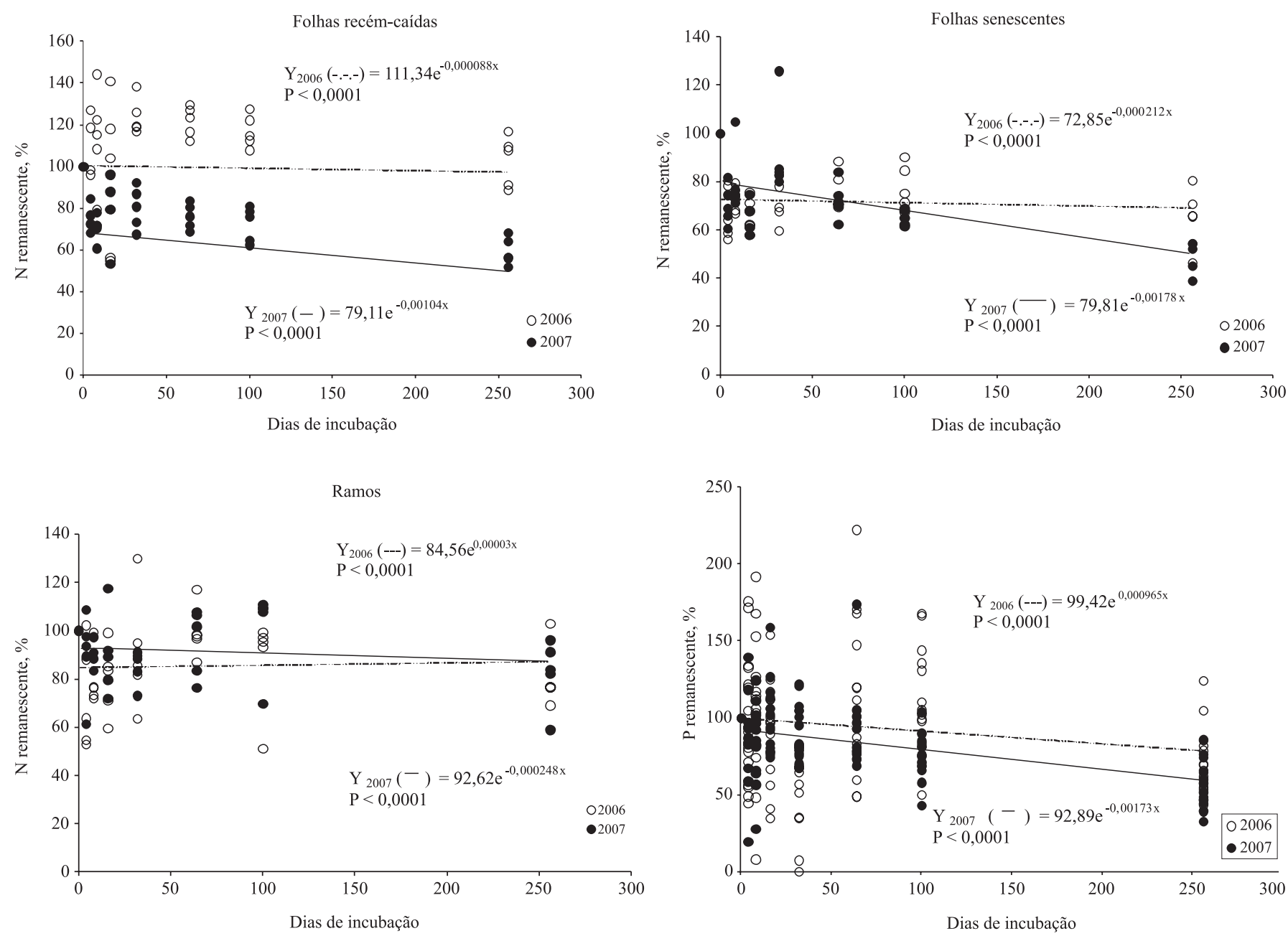

Figura 3 - Mineralização líquida de nitrogênio e fósforo de serrapilheira de sabiá, dados de todos os tratamentos conforme os períodos de incubação. 


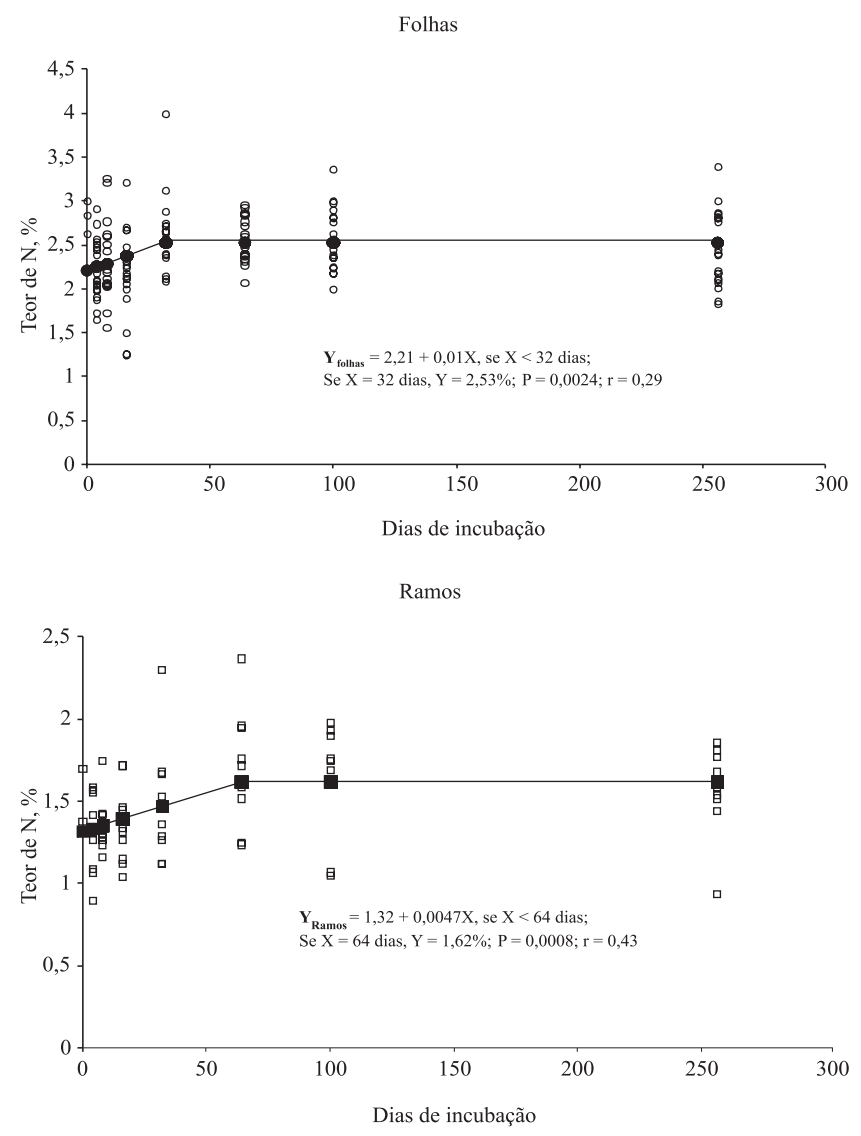

Figura 4 - Teor de nitrogênio (\%) de serrapilheira de folhas e ramos de sabiá, conforme os períodos de incubação.

\section{Conclusões}

Há diferenças nas taxas de mineralização das frações de serrapilheira distintas, notadamente entre folhas e ramos. O modelo exponencial negativo é utilizado para o desaparecimento de nutrientes e relação carbono/ nitrogênio, enquanto a concentração de nutrientes na serrapilheira ao longo do período de incubação segue o modelo platô linear. Há grande variação entre anos. Apesar do alto teor de nitrogênio total observado na serrapilheira de sabiá, sua decomposição é lenta, o que pode reduzir as perdas de nutrientes no bosque, aumentar sua sustentabilidade e diminuir os possíveis efeitos deletérios ao ambiente.
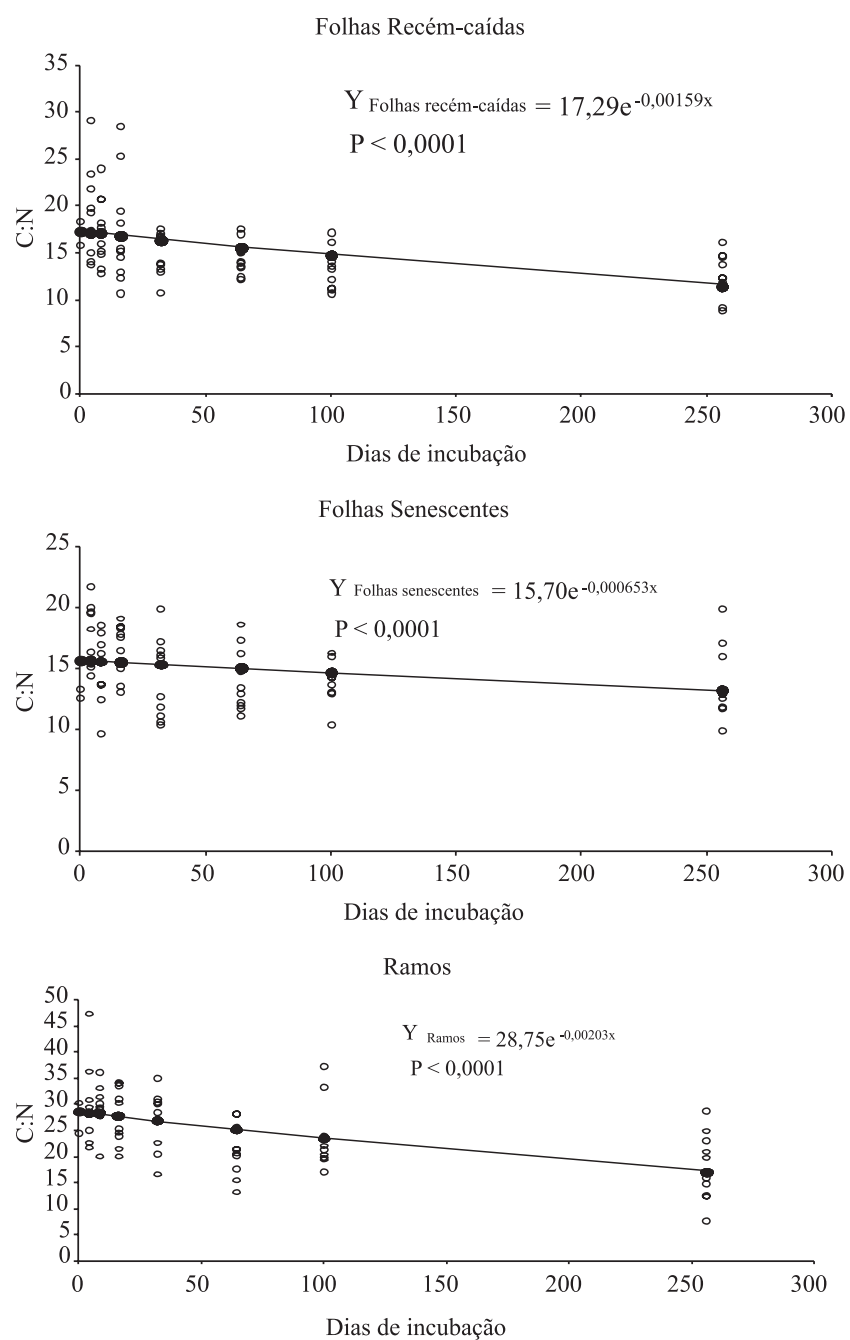

Figura 5 - Relação carbono/nitrogênio de diferentes frações de serrapilheira de sabiá, conforme os períodos de incubação.

\section{Referências}

AITA, C.; GIACOMINI, S.J. Decomposição e liberação de nitrogênio de resíduos culturais de plantas de cobertura de solo solteiras e consorciadas. Revista Brasileira de Ciência dos Solos, v.27, n.2, p.601-612, 2003.

BEGON, M.; HARPER, J.L.; TOWNSEND, C.R. Ecology: Individuals, populations and communities. 3.ed. Oxford: Blackwell Science, 1996. 1087p.

BERTOL, L.; LEITE, D.; ZOLDAN, JR.W.A. Decomposição dos resíduos de milho e variáveis relacionadas. Revista Brasileira de Ciência do Solo, v.28, n.2, p.369-375, 2004.

BEZERRA NETO, E.; BARRETO, L.P. Métodos de análises químicas em plantas. Recife: UFRPE, 2004. p.165.

BONITO, G.M.; COLEMAN, D.C.; HAINES, B.L. et al. Can nitrogen budgets explain differences in soil nitrogen mineralization rates of forest stands along an elevation gradient forest ecology and management. Forest Ecology and Management, v.176, n.3, p.563-574, 2003. 
CHAGAS, E.; ARAÚJO, P.A.; TEIXEIRA, M.G. et al. Decomposição e liberação de nitrogênio, fósforo e potássio de resíduos da cultura do feijoeiro. Revista Brasileira de Ciência do Solo, v.31, n.4, p.723-729, 2007.

COLEMAN, D.C.; CROSSLEY, D.A. Fundamental of soil ecology. London: Academic Press, 1996. 205p.

CPRH, Companhia Pernambucana do Meio Ambiente. Diagnóstico sócio ambiental do litoral norte de Pernambuco. Recife, 2003. 214p.

DUBEUX JR., J.C.B.; SANTOS, H.Q.; SOLLENBERGER, L.E. Ciclagem de nutrientes: perspectivas de aumento da sustentabilidade da pastagem manejada intensivamente. In: PEDREIRA, C.G.S.; MOURA, J.C.; FARIA, V.P. (Eds.) Fertilidade do solo para pastagens produtivas. Piracicaba: FEALQ, 2004. p.357-400.

DUBEUX JR., J.C.B.; SOLLENBERGER, L.E.; INTERRANTE, S.M. et al. Litter decomposition and mineralization in bahia grass pastures managed at different intensities. Crop Science, v.46, n.3, p.1305-1310, 2006.

EMPRESA BRASILEIRA DE PESQUISA AGROPECUÁRIA EMBRAPA. Centro Nacional de Pesquisa de solo. Manual de métodos de análises de solo. Rio de Janeiro: CNPS, 1997. $212 p$.

FERNANDES, M.M.; PEREIRA, M.G.; MAGALHAES, L.M.S. et al. Aporte e decomposição de serrapilheira em áreas de floresta secundária, plantio de sabiá (Mimosa caesalpiniaefolia Benth.) e andiroba (Carapa guianensis Aubl.) na flona Mário xavier, RJ. Ciência Florestal, v.16, n.2, p.163-175, 2006.

GAMA-RODRIGUES, A.C.; BARROS, N.F.; SANTOS, M.L. Decomposição e liberação de nutrientes do folhedo de espécies florestais nativas em plantios puros e mistos no Sudeste da Bahia. Revista Brasileira de Ciências do Solo, v.27, n.6, p.1021-1031, 2003.

GONÇALVES, J.L.M.; MENDES, K.C.F.S.; SASAKI, C.M. Mineralização de nitrogênio em ecossistemas florestais naturais e implantados do Estado de São Paulo. Revista Brasileira de Ciência do Solo, v.25, n.3, p.601-616, 2001.

HEAL, O.W.; ANDERSON, J.M.; SWIFT, M.J. Plant litter quality and decomposition: an historical overview. In: CADISCH, D.; GILLER,G.; K.E. (Eds.) Driven by nature: plant litter quality and decomposition. Wallingford: CAB International, 1997. p.3-30.

JACOMINE, P.K.T. Evolução do conhecimento sobre solos coesos no Brasil. In: WORKSHOP COESÃO EM SOLOS DOS TABUlEIROS COSTEIROS, 2002, Aracaju. Anais... Aracaju: Embrapa Tabuleiros Costeiros, 2001. p.19-46.

LIMA, I.C.A.R.; LIRA, M.A.A.; MELLO, A.C.L. Avaliação de sabiazeiro (Mimosa caesalpiniaefolia Benth) quanto a acúleos e preferência por bovinos. Revista Brasileira de Ciências Agrárias, v.3, n.3, p.289-294, 2008.
MCCARTOR, M.M.; ROUQUETTE, F.M.J. Grazing pressure and animal performance from pearlmillet. Journal of Agronomy, v.69, n.6, p.983-987, 1977.

MOURA, O.N.; PASSOS, M.A.A.; FERREIRA, R.L.C. et al. Distribuição de biomassa e nutrientes na parte aérea de Mimosa caesalpiniifolia Benth. Revista Árvore, v.30, n.6, p.877-884, 2006.

SARYILDIZ, T.; ANDERSON, J.M.; KUCUK, M. Effects of tree species and topography on soil chemistry litter quality, and decomposition in Northeas turkey. Soil Biology and Biochemistry, v.37, n.9, p.1695-1706, 2005.

SILVA, D.J.; QUEIROZ, A.C. Análise de alimentos: métodos químicos e biológicos. 3.ed. Viçosa, MG: Universidade federal de Viçosa, 2002. p.235.

SIQUEIRA, J.O.; FRANCO, A.A. Biotecnologia do solo: fundamentos e perspectivas. Lavras: ESAL/FAEP, 1988. p.235.

SOUTO, P.C. Acumulação e decomposição da serrapilheira e distribuição de organismos edáficos em área de caatinga na Paraíba. 2006. 161f. Dissertação (Doutorado em Zootecnia) - Universidade Federal da Paraíba, Areia.

SOUZA, J.A; DAVID, A.C. Deposição de serrapilheira e nutrientes em uma mata não minerada e em plantações de bracatinga (Mimosa scabrella) e de eucalipto (Eucalyptus saligna) em áreas de mineração de bauxita. CERNE, v.7, n.1, p.101-113, 2001.

SOUZA, S.M.; LIMA, P.C.F. Caracterização de sementes de algumas espécies florestais do Nordeste. In: CONGRESSO NACIONAL SOBRE ESSÊNCIAIS NATIVAS, 1982, Campos do Jordão. Revista do Instituto florestal, v.16, n.2, p.1156-1167, 1982.

STATISTICAL ANALYSIS SYSTEM - SAS. SAS statistics user's guide. Release version 6. Cary: SAS, 1996. (CD-ROM).

TAYLOR, B.R.; PARKINSON, D.; PARSONS, W.F.J. Nitrogen and lignin content as predictors of litter decay rates: a microcosm test. Ecology, v.70, n.1, p.97-104, 1989.

VUONO, Y.S.; DOMINGOS, M.; LOPES, M.I.M.S. Decomposição da serrapilheira e liberação de nutrientes na floresta da Reserva Biológica de Paranapiacaba, sujeita aos poluentes atmosféricos de Cubatão, São Paulo, Brasil. Hoehnea, v.16, n.1, p.179-193, 1989.

WAGNER, G.H.; WOLF, D.C. Carbon transformation and soil organic matter formations. In: SYLVIA, D.M.; FUHRMAN, J.; HARTEL, P. et al. (Eds.) Principles and applications of soil microbiology. Englewood Cliffs: Prentice Hall, 1999. p.218-258.

WARDLE, D.A.; YEATES, G.W.; WATSON, R.N. et al. The detritus food-web and the diversity of soil fauna a indicators of disturbance regimes in agroecosystems. Plant and soil, v.170, n.1, p.35-43, 1995.

WOOD, T.G. Fild investigations on the decomposition of leaves of Eucalyptus delegatensis in relation to environmental factors. Pedobiologia, v.14, n.1, p.343-371,1974. 